\title{
Comprehensive gene expression analyses in pluripotent stem cells of a planarian, Dugesia japonica
}

\author{
NORITO SHIBATA *,1, TETSUTARO HAYASHI ${ }^{2}$, RYUTARO FUKUMURA ${ }^{3}$, JUNSUKE FUJII ${ }^{4}$, \\ TOMOMI KUDOME-TAKAMATSU ${ }^{2}$, OSAMU NISHIMURA ${ }^{1}$, SYOZO SANO ${ }^{4}$, FUYAN SON ${ }^{3}$, \\ NOBUKO SUZUKI ${ }^{3}$, RYOKO ARAKI ${ }^{3}$, MASUMI ABE ${ }^{3}$ and KIYOKAZU AGATA*,4 \\ ${ }^{1}$ Global COE Program: Evolution and Biodiversity, Grad. School of Science, Kyoto Univ. ${ }^{2}$ Center for Dev. Biol., \\ RIKEN, ${ }^{3}$ Transcriptome Research Center, NIRS and ${ }^{4}$ Dept. Biophysics, Grad. School of Science, Kyoto Univ., Japan
}

\begin{abstract}
The neoblasts are the only somatic stem cells in planarians possessing pluripotency, and can give rise to all types of cells, including germline cells. Recently, accumulated knowledge about the transcriptome and expression dynamics of various pluripotent somatic stem cells has provided important opportunities to understand not only fundamental mechanisms of pluripotency, but also stemness across species at the molecular level. The neoblasts can easily be eliminated by radiation. Also, by using fluorescence activated cell sorting (FACS), we can purify and collect many neoblasts, enabling identification of neoblast-related genes by comparison of the gene expression level among intact and X-ray-irradiated animals, and purified neoblasts. In order to find such genes, here we employed the high coverage expression profiling (HiCEP) method, which enables us to observe and compare genome-wide gene expression levels between different samples without advance sequence information, in the planarian $D$. japonica as a model organism of pluripotent stem cell research. We compared expression levels of $\sim 17,000$ peaks corresponding to independent genes among different samples, and obtained 102 peaks as candidates. Expression analysis of genes identified from those peaks by in situ hybridization revealed that at least $\mathbf{4 2}$ genes were expressed in the neoblasts and in neoblast-related cells that had a different distribution pattern in the body than neoblasts. Also, single-cell PCR analysis of those genes revealed heterogeneous expression of some genes in the neoblast population. Thus, using multidimensional gene expression analyses, we were able to obtain a valuable data set of neoblast-related genes and their expression patterns.
\end{abstract}

KEY WORDS: planarian, pluripotent stem cell, HiCEP, comprehensive gene expression analysis

\section{Introduction}

Stem cells are extremely important cells not only during embryogenesis, but also during the life span of adult individuals. Fundamental features of stem cells are maintenance of the stem cell population and production of differentiated cells. These abilities are observed in the stem cells regardless of species and their differentiation ability. These general features imply the existence of common molecular mechanisms, underlying the regulation of stem cells among different tissues and across species in different taxa. In order to elucidate "stemness" in terms of the molecular signature of stem cells, comparative transcriptome analyses have been conducted among various types of stem cells in mammals. Although it has been reported that adult somatic stem cells exist in many species of invertebrates as well as vertebrates (Agata et al., 2006), comparative gene expression analysis across those species, especially in invertebrates, is still poor because of lack of information about stem cell-specific gene sets in various invertebrates. Examining common features of stemness across species at the molecular level, however, might bring us very important knowledge not only about stem cell biology, but also regarding

Abbreviations used in this paper: FACS, flourescent activated cell sorting; FBSC-PCR, FACS-based single cell PCR; HiCEP, high coverage expression profiling.

\footnotetext{
*Address correspondence to: Norito Shibata. Global COE Program, Division of Biological Science, Graduate School of Science, Kyoto University, KitashirakawaOiwake, Sakyo-ku, Kyoto 606-8502, Japan. Tel/Fax: +81-75-753-4261. e-mail: shiba@mdb.biophys.kyoto-u.ac.jp or Kiyokazu Agata. Department of Biophysics, Graduate School of Science, Kyoto University, Kitashirakawa-Oiwake, Sakyo-ku, Kyoto 606-8502, Japan. Tel/Fax: +81-75-753-4200. Fax: +81-75-753-4203. e-mail: agata@mdb.biophys.kyoto-u.ac.jp
}

Supplementary Material ( 1 table) for this paper is available at: http://dx.doi.org/10.1387/ijdb.113434ns 
evo-devo or medical applications.

Dugesia japonica, a freshwater planarian species, has robust regenerative ability, by which almost any small fragments from the body except for in front of the eyes and in the pharynx can regenerate into complete functional animals within 1 week after amputation. Adult stem cells in freshwater planarians, called as neoblasts, can give rise to all types of somatic cells during regeneration (Newmark \& Sánchez Alvarado 2000). Also, germline cells are produced from the neoblasts in the adult body (Sato et al., 2006). Furthermore, the neoblasts supply differentiated cells in intact animals during tissue homeostasis (Newmark and Sánchez Alvarado 2000). X- or gamma-ray irradiation can specifically eliminate the neoblasts, and irradiated animals lose their regenerative ability. Transplantation of a neoblast-rich fraction can restore the regenerative ability of the $X$-ray-irradiated animals, indicating that regeneration of planarians depends on the neoblasts (Baguñà et al., 1989). In addition to those intriguing stem cell features in planarians, recent methodological advances such as in situ hybridization for mRNA detection, lineage tracing by BrdU-labeling, RNA interference (RNAi) for gene knockdown, purification of the neoblasts by fluorescence activated cell sorting (FACS) and single cell PCR based on FACS, make planarians a good animal for stem cell research (Hayashi et al., 2006; Hayashi et al., 2010; Newmark and Sánchez Alvarado 2000; Sánchez Alvarado and Newmark 1999; Umesono et al., 1997).

Thus, much research at the molecular level on the neoblasts has been reported, and information about the expression and function of specific genes is accumulating. The foremost molecular feature of the neoblasts in $D$. japonica is the expression and functions of a number of RNA-binding proteins encoded by germline-specific genes (Shibata et al., 2010). Vasa, PL10/DDX3 and Me31B are DEAD box RNA helicases expressed in germline cells in other animals. In D. japonica, those genes, Djvas-1, DjvlgA and Djcbc-1 respectively, are expressed in the neoblasts (Rouhana et al., 2010; Shibata et al., 1999; Yoshida-Kashikawa et al., 2007). Also, Djpum, a member of the PUF-domain family that acts in germline cells in flies and nematodes, is expressed and functions in the neoblasts (Salvetti et al., 2005). Furthermore, expression of piwi homolog genes, a subfamily of the Argonaute family whose mutants show severe defects of the germline in flies and mice, and expression of bruli, encoding a member of the Bruno-like family of proteins that represses translation of osk in germline cells in flies, is observed in the neoblasts in $D$. japonica as well as in Schmidtea mediterranea, a related planarian species (reviewed by Shibata et al., 2010). RNAi experiments revealed that RNA-binding proteins, including those encoded by germline-specific genes, are involved in the maintenance, proliferation or differentiation of the neoblasts in planarians (reviewed by Shibata et al., 2010).

Also, minichromosome maintenance2, 3 (DjMCM2, 3) and proliferating cell nuclear antigen (Djpcna) related to the process of DNA replication during cell proliferation have been reported to be neoblast-specific genes in D. japonica (Orii et al., 2005; Salvetti et al., 2000). All of these gene identifications are based on homology with known genes in other animals. Although a considerable number of neoblast-specific genes have been obtained by such homology-based methods, such approaches have some biases depending on each researcher that might make it difficult to obtain the overall gene expression profile of the neoblasts. To resolve this issue, genome-wide comprehensive gene expression analysis would be a beneficial approach.
The major method of comprehensive gene expression analysis comparing expression levels between different samples is hybridization-based assays such as microarray analysis. Although microarrays can compare the expression of numerous genes between different samples, the method needs sequence information of a gene set from an EST or genome database. Indeed, microarray experiments using an EST database in D. japonica (using a set of 600 genes) and $S$. mediteranea (using a set of 3,435 genes) could identify many genes expressed in the neoblasts by comparison of the gene expression level between intact and X-ray irradiated planarians (Eisenhoffer et al., 2008; Rossi et al., 2007). Also, a method of transcriptome analysis that does not require any advance sequence information about gene set is available. Because this method, named HiCEP (high coverage expression profiling) has been developed through substantial improvement of the amplified fragment length polymorphism (AFLP), we can detect individual genes as different lengths of PCR fragments by electrophoresis genome widely, and can compare the expression levels of each gene between samples as a difference of fluorescent intensity without any sequence information (Fukumura et al., 2003). In embryonic stem cells (ES cells), about 40,000 transcripts including novel and non-coding genes have been identified by HiCEP (Araki etal., 2006). Thus, HiCEP is a suitable method for accumulating information about gene expression in organisms that have incomplete or lack of gene sequence information.

Here, we report genome-wide comprehensive comparison of gene expression between intact planarians, X-ray-irradiated planarians and purified neoblasts using FACS by HiCEP. Also, we confirmed the expression of HiCEP clones by several methods: in situ hybridization, quantitative RT-PCR (qPCR) and FACS-based single cell PCR (FBSC-PCR). The results showed that we could obtain many neoblast specific genes which showed different expression patterns, and also could demonstrate heterogeneity of the neoblasts.

\section{Results}

\section{Preparation of samples and experimental procedure for HiCEP analysis in D. japonica}

In order to identify neoblast-specific genes, we used three samples, namely, intact and X-ray-irradiated planarians and purified neoblasts. Planarians were irradiated with $160 \mathrm{cGy}$ of X-rays, which was a sufficient dose to eliminate the neoblasts completely (Yoshida-Kashikawa et al., 2007). X-ray-irradiated animals lost regenerative ability, and then died within 3 weeks after irradiation. Cells of $D$. japonica have been classified into three cell fractions, $\mathrm{X} 1, \mathrm{X} 2$ and $\mathrm{XIS}$, according to their size and DNA contents by FACS (Hayashi et al., 2006). The X1 fraction is composed of neoblasts in S/G2/M-phase of the cell cycle (Hayashi et al., 2006, 2010). $\mathrm{X} 2$ is a mixed fraction of the neoblasts in G1-phase and some differentiated cells, and the XIS fraction comprises several types of differentiated cells (Hayashi et al., 2006, 2010). We collected about $1 \times 10^{7}$ cells from the mixed-fraction of X1 and X2 for HiCEP analysis as a neoblast-rich sample. First, we prepared total RNA from non-irradiated [X-ray(-)], X-ray irradiated animals [X-ray (+)] and cells from the $X 1$ and 2 fractions (X1/2, Fig. 1). Synthesized cDNAs of each sample were digested with Mspl, followed by Mspl adapter ligation (Fig. 1). The cDNAs from poly (A) + RNAs were collected and digested with Msel, followed by ligation of Msel adaptor 


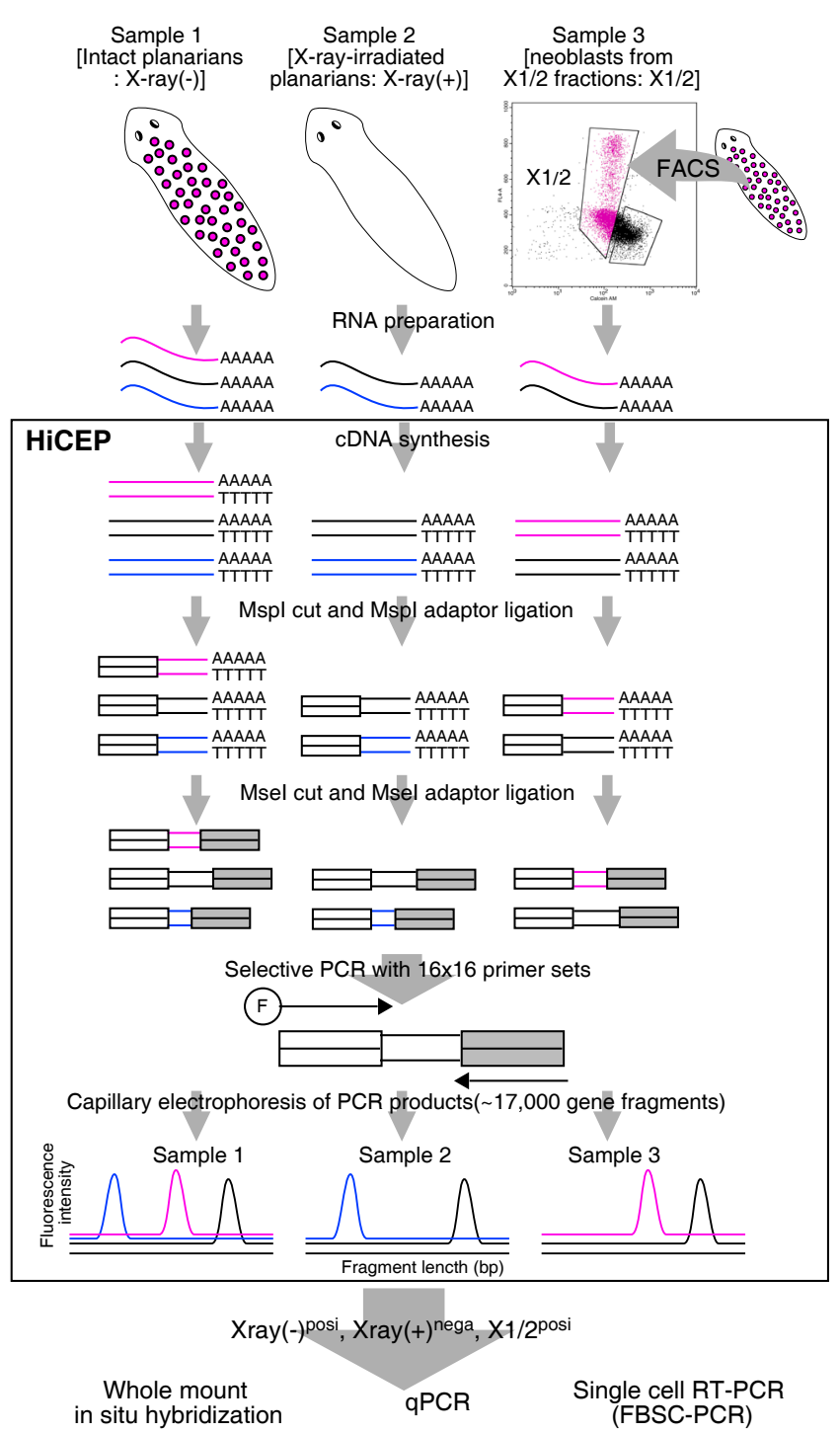

Fig. 1. Schematic drawing of the high coverage expression profiling (HiCEP) experimental procedure. For details see text.

(Fig. 1). Selective PCR using the $16 \times 16$ primer sets was carried out, and the products were analyzed by capillary electrophoresis (Fig. 1: Fukumura et al., 2003). As a result, we detected each PCR product as a peak with a particular length and intensity in each sample. We expected that the peaks of candidate genes would be positive in the non-irradiated planarians, negative or decreased in the $\mathrm{X}$-ray-irradiated planarians, and positive in the neoblast-rich sample [X-ray (-) $)^{\text {posi }}, / \mathrm{X}-\mathrm{ray}(+)^{\text {nega }} / \mathrm{X} 1 / 2^{\text {posi }}$; as indicated for the red peak in Fig. 1]. The obtained candidate genes were then subjected to the following expression analyses (Fig. 1).

\section{Comparison of gene expression levels among the different samples by HiCEP in D. japonica}

We performed HiCEP analysis twice for each sample to check the reproducibility. Consequently, we detected about 17,000 peaks in total in the X-ray(-) sample. The expression levels of 318 peaks showed an X-ray (-) $)^{\text {posi } / X-r a y ~}(+)^{\text {nega }}$ pattern [more than $50 \%$ reduction in the $\mathrm{X}$-ray(+)]. Among them, 102 peaks showed the expected

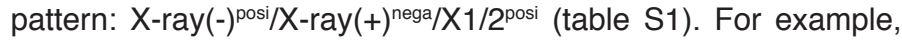

the peak named A3-X-2/HEX was greatly reduced in the X-ray (+) sample in the two experiments (Fig. 2A). A peak with same length was observed in the X1/2 sample (Fig. 2A). Also, the peak D1-I-2/ HEX showed a similar result (Fig. 2B).

By sequence analysis of several peaks, 110 kinds of gene fragments from the 102 peaks were found, indicating that some peaks were composed of multiple fragments, as was also observed in the transcriptome analysis of ES cells by HiCEP (Araki et al., 2006; Table S1). Among them, 86 fragments were matched to clones in the EST database of $D$. japonica. We found that at least 13 fragments were derived from 6 kinds of EST clones, suggesting that there was polymorphism or alternative splicing in those clones. Fifty of the 78 independent EST clones matched HiCEP fragments showing homology or similarity to genes in other animals (Table S1). Although we extended some fragment sequences, which did not match to any EST clones, by 5'RACE, such as \#002 (C3-I-2) NED) and \#005 (G4-I-2/HEX), we did not finding clone matching those fragments in the EST database or any homology with genes
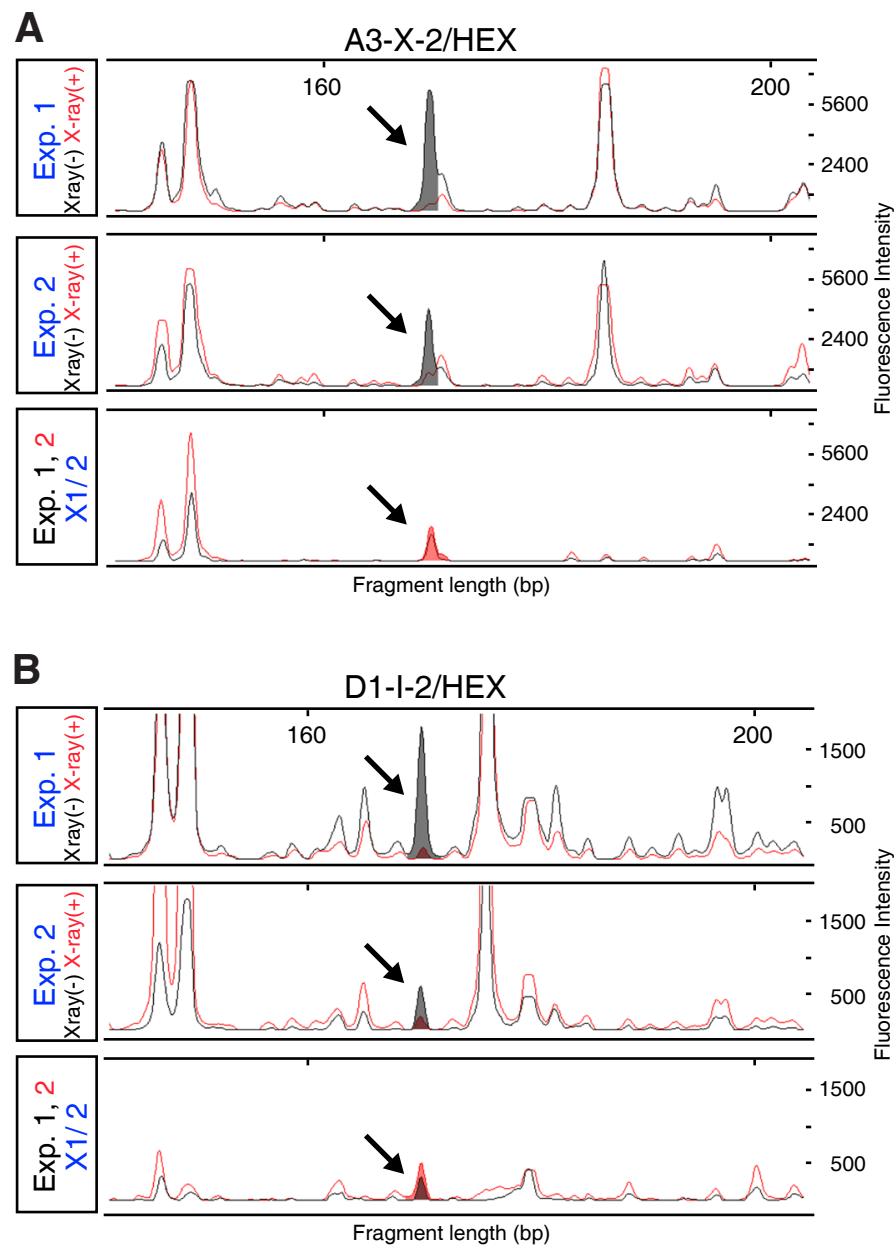

Fig. 2. Examples of comparison of expression level of gene fragments between X-ray(-), X-ray(+) and X1/2 samples by HiCEP. (A) Expression pattern of A3-X-2/HEX. (B) Expression pattern of D1-I-2/HEX. Black peaks in experiments 1 and 2 (Exp. 1 and 2) indicate expression levels of genes in the X-ray(-) sample. Red peaks in experiments 1 and 2 (Exp. 1 and 2) indicate expression levels of genes in the $X$-ray $(+)$ sample. Black and red peaks in Exp.1, 2 indicate gene expression in the X1/2 sample. Arrows indicate gene fragments showing the $X$-ray $(-)^{\text {posi }} / X$-ray $(+)^{\text {nega }} / X 1 / 2^{\text {posi }}$ pattern. 
in other animals (Table S1). For the other non-matched fragments, 5'RACE failed to extend the sequence. Then, the EST-matched clones and the 2 non-matched clones were subjected to the next analysis.

Expression analyses of HiCEP genes by in situ hybridization

To confirm the stem-cell-expressed genes identified by HiCEP analysis, called HiCEP clones, we performed whole-mount in situ hybridization (Fig. 3). The results showed that 42 independent HiCEP clones derived from 46 HiCEP fragments were specifically expressed in X-ray-sensitive cells. Among those clones, 16 did not show any homology or similarity with any known genes in other organisms (Table 1), whereas \#001 (unknown) was similar to NB.32.1g, a novel gene in $S$. mediterranea whose function is not clear. (Eisenhoffer et al., 2008). As mentioned above, many kinds of RNA-binding protein genes, including germline-specific genes, are expressed in the neoblasts of $D$. japonica (reviewed by Shibata et al., 2010). In our analyses, \#008 (piwiA; a homolog of piwi, Yoshida-Kashikawa et al., 2007, Hayashi et al., 2010, Rouhana et al., 2010) and \#028 (a DEAD box family gene) were obtained as genes containing RNA-binding motifs (Table S1). Also, we found a histone RNA hairpin-binding protein [\#024(hRNAhbp)], which is required for translation of histone mRNA (Allard et al., 2005), and two ribosomal proteins [\#013 (rpL44; a ribosomal pro-

TABLE 1

\section{LIST OF THE HICEP CLONES EXPRESSED IN THE NEOBLASTS}

\begin{tabular}{|c|c|c|c|c|c|}
\hline Fragment ID & Fragment length (bp) & Clone \# & Homology (species) & $\begin{array}{l}\text { Published Clone ID in } \\
\text { EST (gene name) }\end{array}$ & E value \\
\hline A3-X-2/HEX & 169.62 & 001 & NB.31.1g [Schmidtea mediterranea] & 05955HH & $4 \mathrm{E}-16$ \\
\hline C3-I-2/NED & 104.64 & 002 & $\mathrm{~N} / \mathrm{A}$ & & \\
\hline D3-I-2/HEX & 169.73 & 003 & NB.31.1g [Schmidtea mediterranea] & $=\# 001$ & \\
\hline E11-I-2/FAM & 106.61 & 004 & N/A & $05656 \mathrm{HH}$ & \\
\hline G4-I-2/HEX & 226.98 & 005 & N/A & & \\
\hline E5-I-2/HEX & 163.38 & 006 & zinc finger protein $\mathrm{Ci}-\mathrm{ZF}(\mathrm{C} 2 \mathrm{H} 2)-42$ [Ciona intestinalis] & $02488 \mathrm{HH}$ & $7 \mathrm{E}-11$ \\
\hline C7-I-2/NED & 262.55 & 007 & SWI/SNF-related chromatin binding protein [Schistosoma mansoni] & $02960 \mathrm{HH}$ & $4 \mathrm{E}-29$ \\
\hline E6-I-2/HEX & 107.23 & 008 & Piwi [Botryllus primigenus] & 03609HH (DjpiwiA) & $2 \mathrm{E}-59$ \\
\hline E5-I-2/HEX & 229.27 & 009 & arginine $\mathrm{N}$-methyltransferase 1 [Echinococcus granulosus] & $04361 \mathrm{HH}$ & $2 \mathrm{E}-57$ \\
\hline D3-I-2/FAM & 318.17 & 010 & Nucleoside diphosphate kinase [Aspergillus nidulans FGSC A4] & 06317HH & $4 \mathrm{E}-51$ \\
\hline H6-I-2/FAM & 236.91 & 011 & purinergic receptor P2X1 [Taeniopygia guttata] & 06727HH & $3 \mathrm{E}-21$ \\
\hline B3-I-2/FAM & 177.92 & 012 & purinergic receptor P2X4 [Sus scrofa] & 06974HH (DjP2X-A) & $9 \mathrm{E}-25$ \\
\hline H8-I-2/NED & 196.11 & 013 & ribosomal protein L44 [Chlamys farreri] & & $1 \mathrm{E}-41$ \\
\hline A12-X2-1/NED & 170.48 & 016 & $\mathrm{~N} / \mathrm{A}$ & & \\
\hline D12-I-2/NED & 161.72 & 019 & Zn finger homeodomain 2 [Tribolium castaneum] & & $1 \mathrm{E}-12$ \\
\hline B1-I-2/FAM & 198.82 & 023 & selenophosphate synthetase 1 [Mus musculus] & & $4 \mathrm{E}-43$ \\
\hline B7-I-2/HEX & 160.42 & 024 & Histone RNA hairpin-binding protein [Schistosoma japonicum] & & $2 \mathrm{E}-29$ \\
\hline F2-I-2/FAM & 200.92 & 025 & N/A & & \\
\hline F10-I-2/NED & 138.39 & 028 & similar to DEAD (Asp-Glu-Ala-Asp) box polypeptide 53 [Ciona intestinalis] & & 0.000003 \\
\hline F12-I-2/NED & 138.4 & 029 & similar to DEAD (Asp-Glu-Ala-Asp) box polypeptide 53 [Ciona intestinalis] & $=\# 028$ & \\
\hline F1-I-2/FAM & 430.13 & 030 & Rootletin (Ciliary rootlet coiled-coil protein) [Schistosoma mansoni] & & $1 \mathrm{E}-144$ \\
\hline G6-I-2/HEX & 212.56 & 032 & topoisomerase (DNA) II beta [Mus musculus] & & $3 \mathrm{E}-32$ \\
\hline H4-I-2/FAM & 160 & 033 & $\mathrm{~N} / \mathrm{A}$ & & \\
\hline H6-I-2/FAM & 215.14 & 035 & Sox8b [Takifugu rubripes] & & $1 \mathrm{E}-20$ \\
\hline D9-I-2/NED & 469.49 & 037 & Placenta-specific gene 8 protein [Schistosoma japonicum] & & $1 \mathrm{E}-13$ \\
\hline E9-I-2/FAM & 244.37 & 038 & SMED P53 [Schmidtea mediterranea] & & \\
\hline A11-X2-2/FAM & 105.56 & 040 & Setb protein [Danio rerio] & 02457HH & $8 \mathrm{E}-49$ \\
\hline A4-X2-1/HEX & 276.93 & 041 & similar to DEAD (Asp-Glu-Ala-Asp) box polypeptide 53 [Ciona intestinalis] & $=\# 028$ & \\
\hline B5-I-2/NED & 123.59 & 042 & Putative OPA3-like protein CG13603 [Schistosoma japonicum] & & $4 \mathrm{E}-32$ \\
\hline D3-I-2/FAM & 179.4 & 046 & Dynein intermediate chain 2 [Anthocidaris crassispina] & 03394HH & $5 \mathrm{E}-57$ \\
\hline D9-I-2/FAM & 101.36 & $047-2$ & chaperonin containing t-complex protein 1 gamma subunit tcpg [Schistosoma mansoni] & 03940HH & 0.0 \\
\hline E5-I-2/HEX & 99.47 & 050 & large subunit ribosomal protein 10 [Oigolaimella attenuata] & $04458 \mathrm{HH}$ & $8 \mathrm{E}-59$ \\
\hline E6-I-2/FAM & 147.06 & 051 & $\mathrm{~N} / \mathrm{A}$ & $00998 \mathrm{HH}$ & 0.97 \\
\hline F10-I-2/NED & 76.56 & 054 & N/A & & \\
\hline H3-I-2/NED & 60.99 & 057 & $\mathrm{~N} / \mathrm{A}$ & & \\
\hline H6-I-2/FAM & 62.08 & 058 & N/A & $06441 \mathrm{HH}$ & \\
\hline A6-I-2/NED & 89.7 & 060 & N/A & & \\
\hline C3-I-2/FAM & 84.12 & $061-2$ & NADH dehydrogenase subunit 2 [Metaseiulus occidentalis] & 07117HH & 0.005 \\
\hline C7-I-2/NED & 55.94 & 062 & peroxiredoxins, prx-1, prx-2, prx-3 [Aedes aegypti] & & $1 \mathrm{E}-81$ \\
\hline E10-I-2/FAM & 67.99 & 075 & N/A & $00310 \mathrm{HH}$ & \\
\hline G11-I-2/FAM & 106.67 & 081 & $\mathrm{~N} / \mathrm{A}$ & $=\# 004$ & \\
\hline G2-I-2/FAM & 64.87 & 082 & protein phosphatase $2 \mathrm{C}$ [Schistosoma mansoni] & $00503 \mathrm{HH}$ & $3 E-62$ \\
\hline G6-I-2/FAM & 99.35 & 085 & conserved-hypothetical-protein-[Ixodes-scapularis] & & 0.000006 \\
\hline H1-I-2/FAM & 71.52 & 097 & similar-to-cytochrome-P450-CYP15A1-[Acyrthosiphon-pisum] & & 0.00000004 \\
\hline H5-I-2/FAM & 54.49 & 098 & CDGSH-type Zn finger-containing protein-like protein [Schistosoma mansoni] & & $1 \mathrm{E}-31$ \\
\hline G12-I-2/FAM & 91.73 & 100 & FK506-binding protein [Manduca sexta] & & $2 \mathrm{E}-42$ \\
\hline
\end{tabular}


tein L44 homolog), \#050 (rp10; a large subunit ribosomal protein 10 homolog)]. Notably, \#007 and \#009 clones showed similarity with epigenetics-related proteins, SWI/SNF-related chromatin binding protein (SWI/SNFr) and arginine $\mathrm{N}$-methyltransferase (PRMT), respectively (Table 1). Furthermore, transcription factors and zinc finger proteins were found among the clones [\#006 (zf, a planarian zinc finger protein), \#035 (soxP1, a planarian homolog of sox gene), \#038 (p53, a homolog of p53) \#098 (zf, a planarian zinc finger protein)]. Also, other kinds of genes were obtained by HiCEP as genes expressed in X-ray-sensitive cells (Table 1), for example, a membrane protein P2X homolog, \#012 (P2X-A) or protein phosphatase $2 \mathrm{C}$, \#082 (pp2C), indicating that a lack of bias in the kind of gene obtained by HiCEP.

\#008 (piwiA), showed a typical pattern of neoblast-specific expression, in which the distribution of positive cells was observed in the mesenchymal space from behind the eyes to the tail (Fig. 3C; Yoshida-Kashikawa et al., 2007; Rouhana et al., 2010; Shibata et al., 2010). Cells expressing \#008 (piwiA) completely disappeared in the X-ray-irradiated animals (Fig. 3D), indicating that this gene was specifically expressed in the neoblasts, as previously described (Yoshida-Kashikawa et al., 2007; Rouhana et al., 2010; Shibata et al., 2010). Genes such as \#012 (P2X-A) and \#032 (unknown) showed the same expression patterns as \#008 (piwiA) in intact and X-ray-irradiated animals (data not shown). A similar expression pattern to that of \#008 (piwiA) was observed for \#009 (PRMT) (Fig $3 \mathrm{E})$. Although the expression pattern of \#009 (PRMT) appeared to be identical to that of the neoblast-specific genes in intact animals, in X-ray-irradiated animals, expression in brain neurons was still observed (Fig. 3F). Many HiCEP clones showed this expression pattern, for example, \#005 (unknown), \#007 (SWI/SNFr), \#057 (unknown), and \#100 (FK506-binding protein) (data not shown).

Although expression of \#001 (unknown) disappeared in X-ray-irradiated animals (Fig. 3B), the expression pattern of this clone was different from that of $\# 008$ (piwiA) or \#009 (PRMT) (Fig. 3A). Cells expressing \#001 (unknown) were located in the mesenchymal space from in front of the eyes to the tail. The neoblasts were lacking in front of the eyes (Fig. 3C), suggesting that the cells-expressing \#001 (unknown) are another type of X-ray-sensitive cells. Also, \#038 (p53) showed a similar expression pattern to that of \#001 (unknown).

We found ubiquitous expression patterns of some HiCEP clones, for example \#015 (rpS3; a homolog of ribosomal protein S3 in D.japonica) in intact animals (Fig. 3G). Ubiquitous expression of \#015 (rpS3) was also observed in $X$-ray-irradiated animals, although the expression level of \#015 (rpS3) seemed to be decreased (Fig. 3H). According to these expression patterns, we mainly classified HiCEP clones into 3 types: Type 1, represented by the expression pattern of \#001 (unknown); Type 2, represented by the \#008 (piwiA) or \#009 (PRMT) expression patterns, and Type 3, represented by the expression pattern of \#015 (rpS3). Type 2 could be further categorized into 2 more types according to whether the gene was expressed in the brain or not. Then we named the genes that showed neoblast-specific expression Type $2 \mathrm{~A}$, and that genes that were expressed in both neoblasts and brain Type 2B. Thus, 2 and 40 kinds of genes were categorized into Type 1 and Type 2, respectively.

\section{Confirmation of expression level of several types of genes by $q P C R$}

The expression of various HiCEP genes was also confirmed by qPCR (Fig. 4). The expression levels of Type 1 and Type 2A $\mathrm{HiCEP}$ clones were significantly decreased in the X-ray-irradiated planarians (Fig. 4). Also, the gene expression levels of Type 2B HiCEP clones were greatly decreased, like those of Type 1 and Type 2A clones; however, about $20 \%$ of the expression of some clones, for example \#009 (PRMT), remained in the X-ray-irradiated animals, where it was mainly seen expression in the brain (Fig. 4). Also, about a $40 \%$ reduction of the gene expression level of a Type 3 clone, \#015 (rpS3), was observed in the X-ray-irradiated planarians. In contrast with these changes of the gene expression levels of HiCEP clones, the expression levels of differentiated cell marker genes, e. g., Djsyt as a neural marker and DjMHC-A as a muscle marker were not affected by X-ray irradiation (Fig. 4).

\section{Expression analysis of HiCEP clones by single cell RT-PCR}

Finally, we employed FACS-based single cell RT-PCR (FBSC$\mathrm{PCR}$ ) to investigate the expression of the neoblast-specific HiCEP clones at the single cell level. FBSC-PCR enables us to analyze the expression of many genes in single cells, and to link the gene expression information to the FACS profile using the index-sorting function (Hayashi et al., 2010). We collected 188 cells each from the X1, X2 and XIS fractions (Fig. 5A), and analyzed the gene expression of several HiCEP clones in these cells.

\#008 (piwiA) was expressed in $84 \%$ of the cells in the $\mathrm{X} 1 \mathrm{frac}$ tion and in $34 \%$ of the cells in the X2 fraction consistent with the previous result (Fig. 5B; Hayashi et al., 2010). Cells expressing
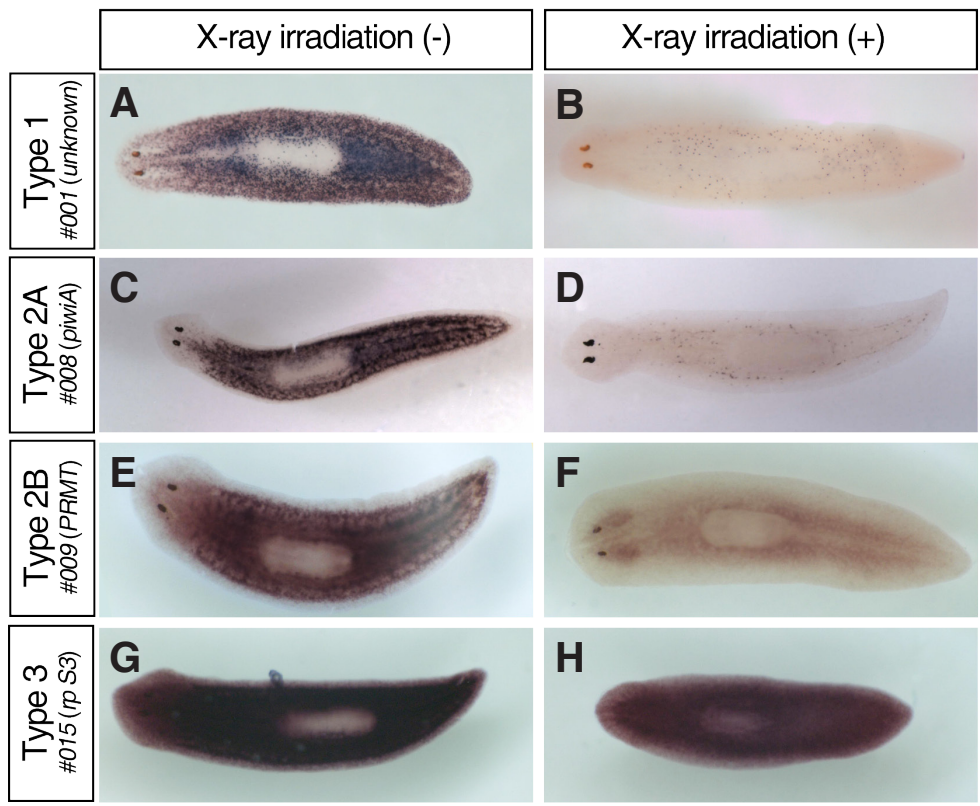

Fig. 3. Expression of Type1, 2 and 3 genes revealed by whole mount in situ hybridization. (A) Expression pattern of Type 1 gene [\#001 (unknown)] in intact animal. (B) Expression pattern of \#001 (unknown) in X-ray-irradiated planarian. (C) Expression pattern of Type 2A gene [\#008 (piwiA)] in intact animal. (D) Expression pattern of \#008 (piwiA) in X-ray-irradiated planarian. (E) Expression pattern of Type 2B gene [\#009 (PRMT)] in intact animal. (F) Expression pattern of \#009 (PRMT) in X-ray-irradiated planarian. (G) Expression pattern of Type 3 gene [\#015 (rpS3)] in intact animal. (H) Expression pattern of \#015 (rpS3) in X-ray-irradiated planarian. 


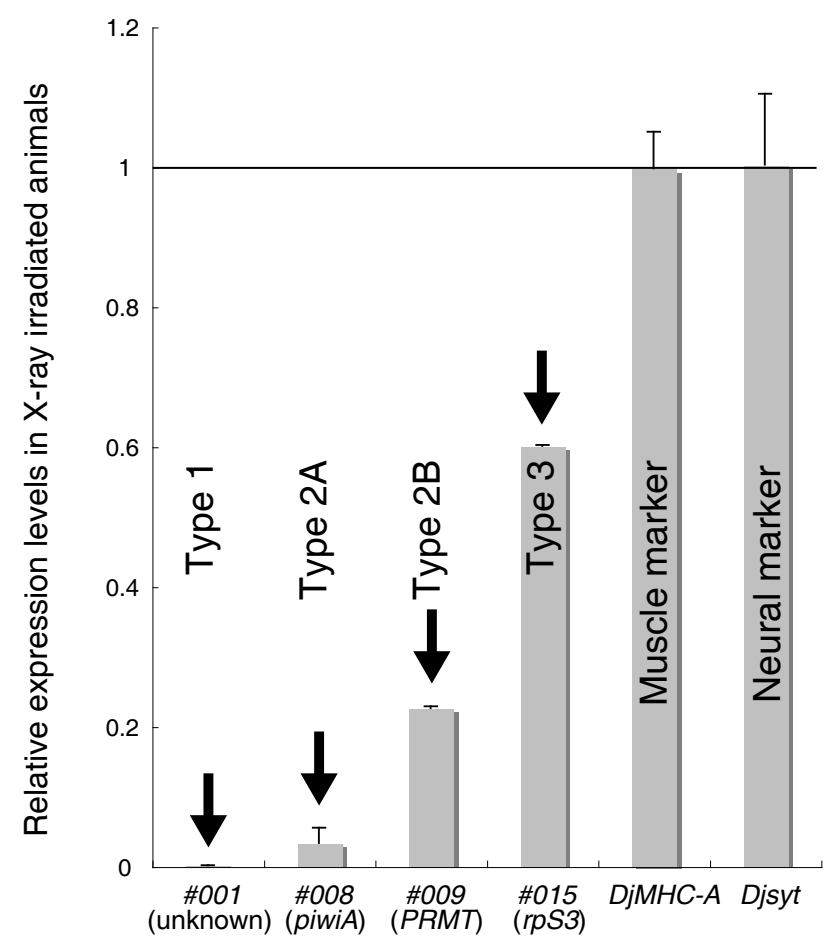

Fig. 4. Confirmation of expression levels of several types of genes by qPCR. 1 on the $Y$ axis indicates relative expression level in intact planarians.

\#008 (piwiA) were specifically sorted into the $\mathrm{X} 1$ and $\mathrm{X} 2$ fractions, in accord with the results from in situ hybridization (Fig. 5B). Another Type 2A gene, \#012 (P2X-A), was also specifically expressed in cells in the $X 1$ and $X 2$ fractions, and almost all \#012 (P2X-A)expressing cells co-expressed \#008 (piwi $A$ ); however, the number of \#012 (P2X-A)-expressing cells was about half of the number of \#008 (piwiA)-expressing cells (Fig. 5 C,H). 50.6\% (80/158) of $\# 008$ (piwiA)-expressing cells in the $\mathrm{X} 1$ fraction co-expressed \#012 (P2X-A), and 27.7\% (18/65) of \#008 (piwiA)-expressing cells in the $\mathrm{X} 2$ fraction were also positive for \#012 (P2X-A), indicating heterogeneity of the neoblasts. Expression of \#007, a Type $2 \mathrm{~B}$ gene, was also detected in cells in the $\mathrm{X} 1$ and $\mathrm{X} 2$ fractions (Fig. 5D). Almost all cells expressing \#008 (piwiA) in the X1 and X2 fractions expressed \#007 (SWI/SNFr) [94.9\% (150/158) and $75.4 \%$ (49/65), respectively] (Fig. 5G). Also, we found that 34 cells in the $\mathrm{X} 2$ fraction were \#007 (SWI/SNFr)-single positive cells as well as 36 cells in the XIS fraction (Fig. 5 D,G). Those \#007 (SWI) $S N F r$ )-single positive cells are expected to be neuronal cells according to the results of in situhybridization. Indeed, 55.6\% of \#007 (SWI/SNFr)-single positive cells in the XIS fraction co-expressed neuronal marker genes, whereas some \#007 (SWI/SNFr)-single positive cells in the $\mathrm{X} 2$ fraction were positive for not only neuronal markers, but also muscular or mucus-producing cell marker genes, suggesting that \#007 (SWI/SNFr)-single positive cells in the X2 fraction might be differentiating cells from the neoblasts (data not shown). A similar expression pattern and sorting profile were observed in the case of \#009, another Type 2B clone, in which $91.2 \%$ of cells in the $X 1$ fraction and $69.2 \%$ of cells in the $X 2$ fraction co-expressed both DjpiwiA and \#009 (PRMT) (Fig. 5E). Also, about $30 \%$ of \#009-single positive cells in the XIS fraction were positive for neuronal cell marker genes (data not shown). We also found heterogeneous gene expression of a Type 2B clone, \#004 (unknown), which showed no homology with any known gene. 35.4\% (56/158) and $29.2 \%(19 / 65)$ of cells expressing \#008 (piwiA) in the $\mathrm{X} 1$ fraction and $\mathrm{X} 2$ fraction, respectively, co-expressed \#004 (unknown) (Fig. 5F). Furthermore, expression of \#012 (P2X-A) was detected in $55.4 \%$ of cells co-expressing DjpiwiA and \#004 (unknown) in the $\mathrm{X} 1$ fraction (Fig. $5 \mathrm{H}$ ), showing the complexity of the neoblast population.

\section{Discussion}

Genome-wide approaches by transcriptome analysis yield significant biological information for understanding molecular fundamentals underlying complex biological phenomena. Also, accumulation of transcriptomic information in several species belonging to different phyla gives us a great opportunity to shed light on the commonality or differences of molecular machinery regulating the same cell type or same phenomenon between species. In order to accumulate transcriptomic information of the neoblast in $D$. japonica, we conducted genome-wide gene expression analysis by HiCEP, which can survey gene expression genome widely and detect the expression levels of those genes simultaneously (Fukumura et al., 2003). Using this unlimited gene expression analysis, we detected $\sim 17,000$ peaks in the intact sample. So far, the genome size of $D$. japonica is estimated to be about 1 1.5 G bp, and the total number of genes is expected to be around 20,000 (Agata and Nishimura. personal communication). Actually, it was observed that some different peaks were derived from the same gene in our results, indicating that the number of peaks did not reflect the number of kinds of genes (Table 1 and S1). However, most of the peaks matched to independent EST clones, suggesting that our analysis could survey genome widely.

\section{Comparison of gene expression levels in the three samples by HiCEP}

By comparison of the gene expression in 5 distinct samples by HiCEP, namely from head-regenerating tissues 12 and 24 hours after amputation, tail-regenerating tissues 12 and 24 hours after amputation, and non-regenerating tissues, Tasaki et al., succeeded in the identification of $\operatorname{DjmkpA}$ (Dugesiajaponica mitogen-activated kinase phosphatase $A$ ) as an early blastema-specific gene (Tasaki et al., 2011). Also in this report, we compared gene expression levels between 3 distinct samples [X-ray(-), X-ray(+) and X1/2], and detected 102 peaks as candidates which showed the expres-

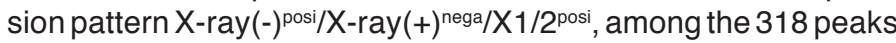
of X-ray(-) $)^{\text {posi }} / X-r a y(+)^{\text {nega }}$. The remaining 216 peaks showed an X-ray(-) posi/X-ray $(+)^{\text {nega }} / \mathrm{X} 1 / 2^{\text {nega }}$ pattern (data not shown). In situ hybridization revealed that a clone of this type was not expressed in the neoblasts (data not shown). Thus, we could narrow down the number of candidate peaks by comparing the gene expression in not only intact and X-ray-irradiated planarians, but also the stem cell-enriched sample collected by FACS.

\section{Genes obtained by HiCEP}

HiCEP enables us to obtain not only known genes, but also novel genes (Araki et al., 2006). In our analysis, we could not find any EST clone matching 24 fragments (Table S1). The sequence of these fragments also did not show any similarity with any known gene in other organisms, although at least 2 clones extended 

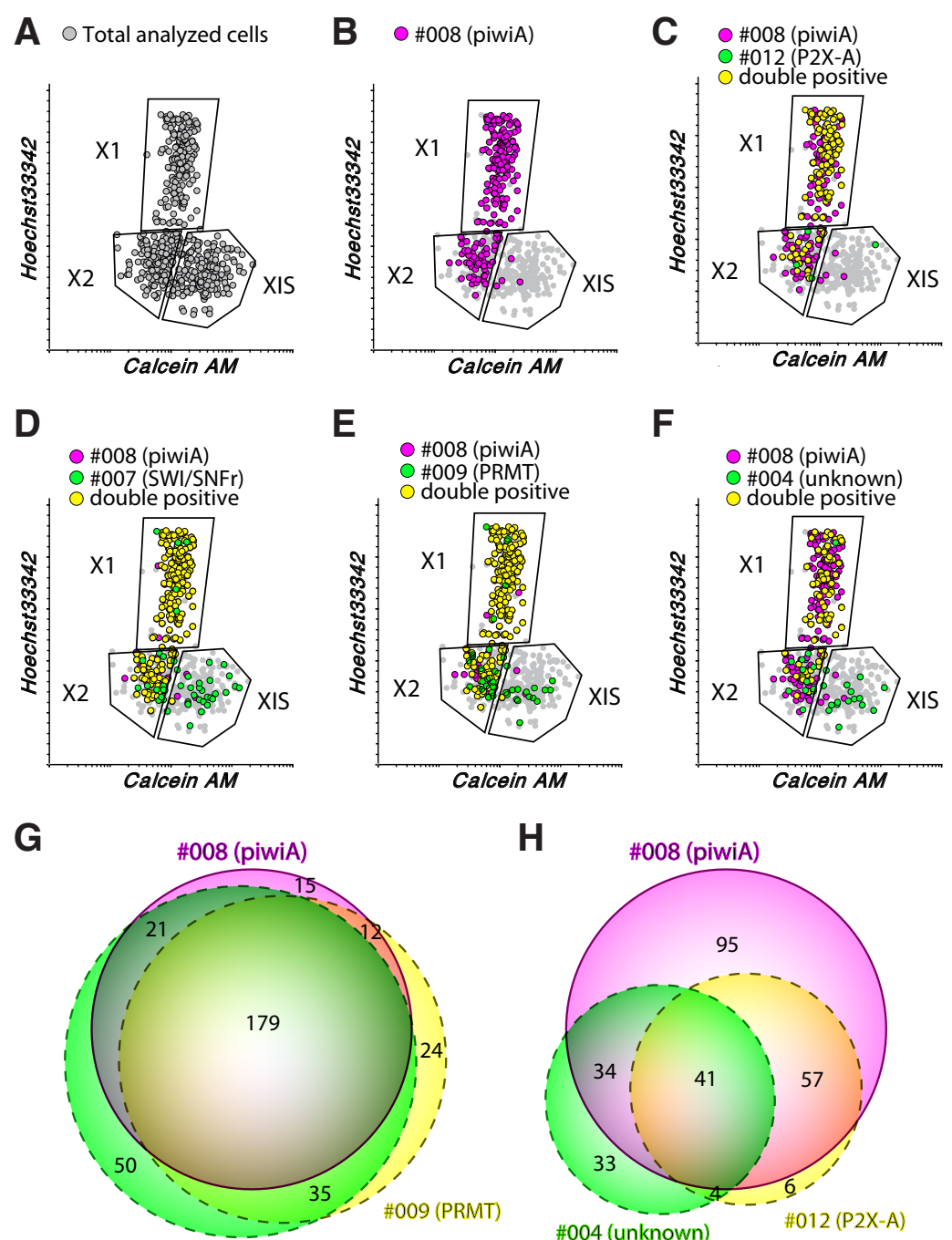

\#007 (Swi/SNFr)

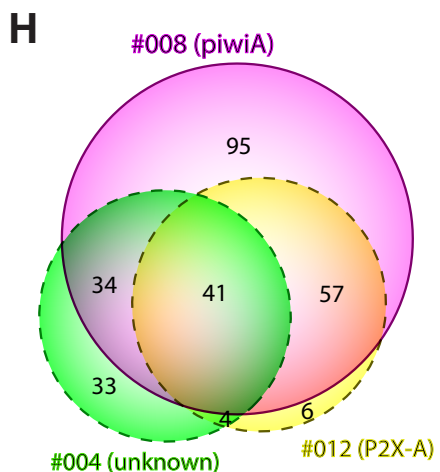

Fig. 5. Single cell gene expression analyses by FACS-based single cell PCR (FBSC-PCR). (A) Total cells in the several fractions used for analysis. (B) Expression of \#008 (piwiA). (C) Co-expression analysis of \#012 (P2X-A) (green) and \#008 (piwiA) (magenta). Yellow dots show double positive cells. (D) Co-expression analysis of \#007 (SWI/SNFr) (green) and \#008 (piwiA) (magenta). Yellow dots show double positive cells. (E) Co-expression analysis of \#009 (PRMT) (green) and \#008 (piwiA) (magenta). Yellow dots show double positive cells. (F) Co-expression analysis of \#004 (unknown) (green) and \#008 (piwiA) (magenta). Yellow dots show double positive cells. (G) Coexpression diagram for \#008 (piwiA) (magenta), \#007 (SWI/SNFr) (green) and \#009 (PRMT) (yellow). The numbers indicate the cell number belonging to each overlapping expression. (H) Co-expression diagram for \#008 (piwiA) (magenta), \#004 (unknown) (green) and \#012 (P2X-A) (yellow). The numbers indicate the cell number belonging to each overlapping expression.

from the fragments by 5'RACE among them were expressed in the neoblasts [\#002 (unknown) and \#005 (unknown)]. Genome information and enrichment of the EST database in $D$. japonica might uncover gene information about the remaining fragments in the future. Thus, we could identify many genes expressed in the neoblasts, not only known genes (30 independent clones), but also novel genes (12 independent clones) by HiCEP analysis.

Previously, microarray analysis (using the Dj600 chip) to obtain neoblast-specific genes in $D$. japonica was carried out (Rossi et al., 2007). In the results, 42 kinds of genes, including 4 genes known to be expressed in the neoblasts, showed reduced expression levels in X-ray-irradiated planarians. Although our analyses revealed that 42 kinds of genes were expressed in the neoblasts or related cells, only 2 genes were overlapping between the results from the Dj600 chip and HiCEP [\#010 (ndpk; nucleoside diphosphate kinase) and \#040 (setb)]. The foremost difference in the results between the Dj600 chip and HiCEP is that unknown (novel) genes expressed in the neoblasts can be found in the result of HiCEP, because the HiCEP method is independent of sequence information.

\section{In situ hybridization revealed different expression patterns among HiCEP clones}

We found different expression patterns among HiCEP clones via expression analysis by in situ hybridization. We categorized those expression patterns mainly into 3 types: Type 1, Type 2 and Type 3 (Fig. 3). Although type 2 was the typical distribution pattern of the neoblasts, this pattern was subdivided into 2 more types: Type $2 \mathrm{~A}$ and $\mathrm{B}$, according to difference of expression in the brain. Expression pattern type $2 \mathrm{~B}$, which is expression in the neoblasts and brain neurons, was also observed in the results of extensive analyses of RNA-binding proteins, as well as Type 2A (Rouhana et al., 2010; YoshidaKashikawa et al., 2007), suggesting that there are similar molecular machineries to regulate the neoblasts and neurons (Yoshida-Kashikawa et al., 2007).

Type 3 clones were ubiquitously expressed in planarians, but their expression levels were reduced by X-ray irradiation. \#015 (rpS3) showed a Type 3 expression pattern. rpS3 is known to be a component of the small ribosomal subunit involved in translational initiation (Polakiewicz et al., 1995). Interestingly, multiple functions of rpS3 in addition to translation have been reported, for example, rpS3 is involved in DNA repair after UV irradiation (Jung. et al., 2001; Lee et al., 2002). Also, rpS3 binds to p53 and MDM2, and regulates the p53 level by preventing its degradation (Yadavilli et al., 2009), suggesting that rpS3 is also concerned with apoptosis and cell cycle regulation via the p53 cascade. The neoblasts are a unique somatic cell population possessing proliferative ability, and show sensitivity to X-ray or gamma ray irradiation that is expected to induce DNA breaks and apoptosis (Pellettieri et al., 2009). This implies that \#015 (rpS3) expression in the neoblasts might be relatively higher than that in differentiated cells. This may cause a decrease of the expression level in the X-ray-irradiated animals in spite of the ubiquitous expression of \#015 (rpS3), whereas there is a possibility that expression of \#015 (rpS3) was merely affected by X-ray irradiation in $D$. japonica.

Two of the HiCEP clones showed a Type 1 expression pattern, in which cells expressing the genes were distributed in the mesenchymal space from in front of the eyes to the tail. One of them, \#001 (unknown), showed homology with NB.32.1g, which is a novel gene identified by microarray analysis in $S$. mediterranea (Eisenhoffer et al., 2008). Based on disappearance of the neoblasts followed by cells expressing NB.32.1g after X-ray irradiation, and cell tracing experiment using BrdU, it has been 
proposed that NB.32.1g-expressing cells should be precursor cells of some differentiated cells (Eisenhoffer et al., 2008). It has also been reported that $p 53$ in $S$, mediterranea is involved in the production of cells expressing NB.32.1g (Pearson and Sánchez Alvarado, 2010). Another Type 1 clone was \#038 (p53), indicating that cells expressing Type 1 clones are coincident with cells expressing NB.32.1g in S. mediterranea.

\section{Heterogeneity of the neoblasts revealed by FBSC-PCR}

In the case of ES cells, heterogeneous expression of nanog, which has an important role in maintaining the pluripotency of ES cells, is observed (Chambers et al., 2007). Nanog-expressing ES cells can keep their status as ES cells, whereas Nanog-negative ES cells undergo differentiation or return to the ES cell state (Chambers et al., 2007). Transitions of gene expression along the changing cell status are also observed in hematopoietic stem cells (Wilson et al., 2007). Furthermore, during neurogenesis in fly, expression levels of transcription factors is sequentially changed along the progression of embryogenesis, and these changes are required for proper neural cell production (Isshiki et al., 2001). Thus, manifestation about heterogeneity in a cell population at the molecular and single cell levels will bring us important information to define the cell state.

Classically, the neoblasts were considered to be a unique and homogeneous cell population. However, recent molecular research has demonstrated the heterogeneity of the neoblast population in $D$. japonica. Djpiwi-1, a piwi family gene in $D$. japonica, is expressed in the subpopulation of neobasts located along the longitudinal dorsal midline (Rossi et al., 2006). nanos is expressed in the germline precursors in asexual planarians in D. japonica (Sato et al., 2006). The cells expressing nanos have stem cell features morphologically and express several neoblast specific genes (Sato et al., 2006; Yoshida-Kashikawa et al., 2007), meaning they are a subpopulation of neoblasts. This result was confirmed by the results of FBSC-PCR analysis, in which nanos-positive cells were found in the $\mathrm{X} 1$ fraction, a certain population among DjpiwiA-expressing cells (Hayashi et al., 2010). FBSC-PCR analyses also showed heterogeneity of the neoblasts based on the expression of several genes (Hayashi et al., 2010). Furthermore, FBSC-PCR revealed that genes related to DNA replication are predominantly expressed in the S-phase neoblasts, suggesting complex heterogeneous gene expression in the neoblast population (Hayashi et al., 2010). Here, we also found heterogeneous gene expression in the HiCEP clones (Fig. 5). \#012 ( $P 2 X-A)$ belonging to Type $2 A$ was expressed in about half of the neoblasts positive for DjpiwiA in the $\mathrm{X} 1$ fraction. In the $\mathrm{X} 2$ fraction, \#012( $P 2 X-A)$ - and \#008 (piwiA)-double positive cells were also found. \#012 $(P 2 X-A)$ encodes an ionotropic purinergic receptor, named $D j P 2 X-A$, and functions in maintaining the steady state of cell proliferation of the neoblasts (Sakurai et al., 2012). Although cells positive for DjP2X-A were distributed throughout the body along the anterior-posterior and medio-lateral axis like those positive for DjPiwiA, the DjP2X-A-expressing neoblasts were localized in the outermost layer of the mesenchymal space whereas DjPiwiA single positive neoblasts were observed in a more inner layer, reflecting heterogeneous expression as defined by FBSC-PCR. We do not know the details of regulatory mechanism of $D j P 2 X-A$ expression in the neoblasts, but it might be related to be proliferation state.

\section{Conclusion}

In this work, we surveyed planarian gene expression by HiCEP genome widely, and analyzed the expression of the genes by in situ hybridization, qPCR and single cell RT-PCR. By these multiple gene expression analyses, we could obtain at least 110 gene fragments as candidates, define at least 42 neoblast or related cell-specific genes classified into Type 1, Type $2 A$ and $B$, and could reveal complexity of the gene expression in the neoblast population. These multidimensional data can provide important information not only about planarians, but also about stem cell biology.

The combination of HiCEP and in situ hybridization identified several kinds of neoblast-specific genes including genes predicted to be involved in chromatin modification, gene transcription, cell cycle, apoptosis and cell-cell interaction via the cell membrane as well as RNA metabolism. This sequence information expands our knowledge of molecular fundamentals in planarian stem cells. Through functional analyses of these genes in the future, we will be able to interconnect several molecular cascades in overall neoblast regulation. Furthermore, this gene set of the neoblasts in $D$. japonica, in combination with previous information (reviewed by Shibata et al., 2010), can be used to reveal common features of stemness across species by comparing gene sets among organisms. The data from the combination of in situ hybridization and FBSC-PCR will help us to understand the relationship between gene function and nonuniformity of the neoblasts. Also, we can utilize this method for analysis that defines the gene function involved in commitment of the neoblasts to restricted cell lineages after we identify precise cell markers. Thus, these multiple gene expression analyses are very useful for stem cell research not only in planarians, but also in other organisms, and might provide significant information for stem cell biology.

\section{Materials and Methods}

\section{Animals}

The asexual planarians of a clonal strain, SSP (sexualizing special planarian), of $D$. japonica were used. Planarians were kept in autoclaved tap water at $24^{\circ} \mathrm{C}$. They were fed chicken liver every 2 weeks for maintenance. Planarians were starved for 7-14 days prior to experiments. About 8-mmlong planarians were sacrificed for the neoblast collections by FACS and FBSC-PCR, and up to 6-mm planarians were used for in situ hybridization.

\section{RNA preparation}

Total RNA from the neoblasts collected by FACS was prepared using an RNeasy Mini kit (QIAGEN) for HiCEP. Total RNAs from intact and Xray-irradiated planarians were prepared by the $\mathrm{CsCl}$ cushion method for HiCEP. Total RNAs from intact and X-ray-irradiated animals were prepared using ISOGEN-LS (ISOGEN-LS, Tokyo, Japan) for qPCR.

\section{$X$-ray irradiation}

X-ray irradiation was performed as previously described (YoshidaKashikawa et al., 2007). Planarians placed on wet filter paper on ice were irradiated with 160 cGray (cGy) of X-rays using an X-ray generator (SOFTEX B-4).

\section{HiCEP}

HiCEP analysis was performed as described by Fukumura et al.,2003). Five micrograms of total RNA from each sample was used for first strand cDNA synthesis using a Superscript ${ }^{\mathrm{TM}}$ First-Strand Synthesis System (Invitrogen) with $100 \mathrm{pmol}$ of 5' biotinylated oligo(dT) primer. After synthesis of second strand cDNA (dscDNA), the dscDNA was digested with Mspl 
(Takara, Ohtsu, Japan), followed by Mspl adaptor ligation with T4 DNA ligase (NEB, Beverly, MA). The products ligated with poly(A)-biotin were collected using magnetic beads coated with streptavidin, Dynabeads M-280 streptavidin (Dynal, Oslo, Norway). After washing, the products on the beads were digested with Msel (NEB). The supernatant containing digested fragments was collected, followed by ligation to 10.2 pmol Msel adaptor using T4 ligase.

Using those adaptor-ligated dscDNA fragments, selective PCR based on AFLP was carried out. The 16 sequences of Mspl-NN primers conjugated with fluorescent dye and the 16 sequences of Msel-NN primers were used. The PCR conditions were as follows: $95.0^{\circ} \mathrm{C}$ for $1 \mathrm{~min}, 28$ cycles at $95.0^{\circ} \mathrm{C}$ for $20 \mathrm{sec}, 71.5^{\circ} \mathrm{C}$ for $30 \mathrm{sec}$ and $70^{\circ} \mathrm{C}$ for $1 \mathrm{~min}$, followed by $60.0^{\circ} \mathrm{C}$ for $30 \mathrm{~min}$. The PCR products were loaded on an ABI Prism 310 (Applied Biosystems, Foster City, CA) for electrophoresis. The data analysis was performed using GeneScan 3.1.2 (Applied Biosystems).

The aliquot of HiCEP product was loaded on a $10 \%$ polyacrylamide gel. After silver staining of the gel, appropriate bands matching fragments of interest were cut out. The gel slices were suspended in $50 \mu \mathrm{l}$ of TE buffer (10 mM Tris- $\mathrm{HCl} \mathrm{pH}$ 8.0, 1mM EDTA), and $2 \mu$ of supernatant was used for PCR.

\section{Whole-mount in situ hybridization}

All digoxigenin-labeled RNA probes were prepared using pBluescriptSK(-) vectors containing the insert from the EST clone or PCR II-TOPO (Invitrogen) vector containing PCR product and a digoxigenin-labeling kit according to the manufacturer's instructions (Roche). Manual wholemount in situ hybridization using alkaline phosphatase and 4-nitroblue tetrazolium chloride /5-bromo-4-chloro-3-indolyl-phosphate (NBT/BCIP) color development was carried out as described by Umesono et al., 1997. Also automatic in situ hybridization was carried out by InsituPro (ABIMED, Langenfeld, Germany).

\section{Quantitative reverse transcription-polymerase chain reaction}

First-strand cDNAs complementary to total RNA from intact and X-rayirradiated planarians were synthesized using a QuantiTect, Reverse Transcription kit (GIAGEN). Diluted cDNAs (20X) were used for semi-quantitative reverse transcription-polymerase chain reaction (qPCR). Ten microliters of qPCR mixture was composed of $1 X$ Quantitect SYBR green PCR master mix (QIAGEN), $0.3 \mu \mathrm{M}$ gene primers and diluted cDNA, and incubated in an ABI PRISM 7900 HT (Applied Biosystems). The reaction conditions were as follows: $50^{\circ} \mathrm{C}$ for $2 \mathrm{~min}, 95^{\circ} \mathrm{C}$ for $15 \mathrm{~min}, 50$ cycles of $95^{\circ} \mathrm{C}$ for 15 sec, $60^{\circ} \mathrm{C}$ for $30 \mathrm{sec}$ and $72^{\circ} \mathrm{C}$ for $1 \mathrm{~min}$. To check the products, $95^{\circ} \mathrm{C}$ for $15 \mathrm{sec}, 60^{\circ} \mathrm{C}$ for $15 \mathrm{sec}$ and $95^{\circ} \mathrm{C}$ for $15 \mathrm{sec}$ was added to determine the melting curve at the end of the reaction.

\section{Single cell RT-PCR}

Single cell gene expression analyses using FACS-based single cell RT-PCR (FBSC-PCR) were performed as described by Hayashi et al., (2010). Gene specific primers were as follows:

\section{$D j G 3 P D H$}

FW: ACCACCAACTGTTTAGCTCCCTTAG

RV: GATGGTCCATCAACAGTCTTTTGC

$D j M H C-A$

FW: TCTGAAGAAAGAGCTGATCAAGCTGAACAA

$$
\text { RV: TGGATTTCACAGTAGTCGTACCAGGTGCCA }
$$
Djsyt

FW: GAACTCCGGCATTGGTCGGA

RV: GTTAAGCTTTTGTTCATTAATTGTTTTC \#001 (unknown)

FW: TATGATGAAAATGATAAAGCAACACGAA

RV: CATTCTTTATCCAGTTTTTTTTACTCCATT

\#004 (unknown)

FW: AATTATTGCTTGCGATGGTCTCTG

RV: TATCTCCGCTCATTTTCAATACGG
\#007 (DjSWI/SNFr)

FW: AAAAATGTGGGAGGCATGTAAAGAC

RV: CTTCCTCTTCATGATTACCATTGACC

\#008 (piwiA)

CGAATCCGGGAACTGTCGTAG

RV: GGAGCCATAGGTGAAATCTCATTTG

\#009 (PRMT)

FW: AGTCAATAACGGTGAAGAGATAACTGG

$\mathrm{RV}$ : CCTTCCGACCTACCTCATTCG

\#012 (P2X-A)

FW: GATTTCAACAATGGAATGAATTTTAGATA

RV: AAAATGTGAAACAAGTAGCAGGATCA

\#015 (rpS3)

FW: TGACGGATTAATGATTCACAGTGG

RV: TGAAATCAGGCAAAGGACGC

\section{Acknowledgements}

We thank Dr Elizabeth Nakajima for critical reading of the manuscript and all other laboratory members for their help and encouragement. This work was supported by a Grant-in-Aid for Creative Scientific Research to K. A. (17GS0318), a Grant-in-Aid for Scientific Research on Innovative Areas "RNA regulation" (No. 20112006) to N. S. and the Global COE Program A06 of Kyoto University.

\section{References}

AGATA, K., NAKAJIMA, E., FUNAYAMA, N., SHIBATA, N., SAITO, Y. and UMESONO, Y. (2006). Two different evolutionary origins of stem cell systems and their molecular basis. Semin Cell Dev Biol 17: 503-509.

ALLARD, P., YANG, Q., MARZLUFF, W.F. and CLARKE, H.J. (2005). The stem-loop binding protein regulates translation of histone mRNA during mammalian oogenesis. Dev Biol 286: 195-206.

ARAKI, R., FUKUMURA, R., SASAKI, N., KASAMA, Y., SUZUKI, N., TAKAHASHI, H., TABATA, Y., SAITO, T. and ABE, M. (2006). More than 40,000 transcripts, including novel and noncoding transcripts, in mouse embryonic stem cells. Stem Cells 24: 2522-2528.

BAGUÑ̇̀, J., SALÒ, E. and AULADELL, C. (1989). Regeneration and pattern formation in planarians. III. Evidence that neoblasts are totipotent stem cells and the source of blastema cells. Development 107: 77-86.

CHAMBERS, I., SILVA, J., COLBY, D., NICHOLS, J., NIJMEIJER, B., ROBERTSON, M., VRANA, J., JONES, K., GROTEWOLD, L. and SMITH, A. (2007). Nanog safeguards pluripotency and mediates germline development. Nature 450: 1230-1234

EISENHOFFER, G.T., KANG, H. and SÁNCHEZ ALVARADO, A. (2008). Molecular analysis of stem cells and their descendants during cell turnover and regeneration in the planarian Schmidtea mediterranea. Cell Stem Cell 3: 327-339.

FUKUMURA, R., TAKAHASHI, H., SAITO, T., TSUTSUMI, Y., FUJIMORI, A., SATO, S., TATSUMI, K., ARAKI, R. and ABE, M. (2003). A sensitive transcriptome analysis method that can detect unknown transcripts. Nucleic Acids Res 31: e94.

HAYASHI, T., ASAMI, M., HIGUCHI, S., SHIBATA, N. and AGATA, K. (2006). Isolation of planarian X-ray-sensitive stem cells by fluorescence-activated cell sorting. Dev Growth Differ 48: 371-380.

HAYASHI, T., SHIBATA, N., OKUMURA, R., KUDOME, T., NISHIMURA, O., TARUI, H. and AGATA, K. (2010). Single-cell gene profiling of planarian stem cells using fluorescent activated cell sorting and its "index sorting" function for stem cell research. Dev Growth Differ 52: 131-144.

ISSHIKI, T., PEARSON, B., HOLBROOK, S. and DOE, C.Q. (2001). Drosophila neuroblasts sequentially express transcription factors which specify the temporal identity of their neuronal progeny. Cell 106: 511-521.

JUNG, S.O., LEE, J.Y. and KIM, J. (2001). Yeast ribosomal protein S3 has an endonuclease activity on AP DNA. Mol Cells 12: 84-90.

LEE, C.H., KIM, S.H., CHOI, J.I., CHOI, J.Y., LEE, C.E. and KIM, J. (2002). Electron paramagnetic resonance study reveals a putative iron-sulfur cluster in human rpS3 protein. Mol Cells 13: 154-156.

NEWMARK, P.A. and SÁNCHEZALVARADO, A. (2000). Bromodeoxyuridine specifically labels the regenerative stem cells of planarians. Dev Biol 220: 142-153. 


\section{N. Shibata et al.}

ORII, H., SAKURAI, T. and WATANABE, K. (2005). Distribution of the stem cells (neoblasts) in the planarian Dugesia japonica. Dev Genes Evol 215: 143-157.

PEARSON, B.J. and SÁNCHEZ ALVARADO, A. (2010). A planarian p53 homolog regulates proliferation and self-renewal in adult stem cell lineages. Development 137: 213-221.

PELLETTIERI, J., FITZGERALD, P., WATANABE, S., MANCUSO, J., GREEN, D.R. and SÁNCHEZ ALVARADO, A. (2009). Cell death and tissue remodeling in planarian regeneration. Dev Biol 338: 76-85.

POLAKIEWICZ, R.D., MUNROE, D.J., SAIT, S.N., TYCOWSKI, K.T., NOWAK, N.J., SHOWS, T.B., HOUSMAN, D.E. and PAGE, D.C. (1995). Mapping of ribosomal protein S3 and internally nested snoRNA U15A gene to human chromosome 11q13.3-q13.5. Genomics 25: 577-580.

ROSSI, L., SALVETTI, A., LENA, A., BATISTONI, R., DERI, P., PUGLIESI, C., LORETI, E. and GREMIGNI, V. (2006). DjPiwi-1, a member of the PAZ-Piwi gene family, defines a subpopulation of planarian stem cells. Dev Genes Evol 216: 335-346.

ROSSI, L., SALVETTI, A., MARINCOLA, F.M., LENA, A., DERI, P., MANNINI, L., BATISTONI, R., WANG, E. and GREMIGNI, V. (2007). Deciphering the molecular machinery of stem cells: a look at the neoblast gene expression profile. Genome Biol 8: R62.

ROUHANA, L., SHIBATA, N., NISHIMURA, O. and AGATA, K. (2010). Different requirements for conserved post-transcriptional regulators in planarian regeneration and stem cell maintenance. Dev Biol 341: 429-443.

SAKURAI, T., LEE, H., KASHIMA, M., SAITO, Y., HAYASHI, T., KUDOME-TAKAMATSU, T., NISHIMURA, O., AGATA, K. and SHIBATA, N. (2012). The planarian P2X homolog in the regulation of asexual reproduction. Int. J. Dev. Biol. 56: 173-182. (doi: 10.1387/ijdb.113439ts).

SALVETTI, A., ROSSI, L., DERI, P. and BATISTONI, R. (2000). An MCM2-related gene is expressed in proliferating cells of intact and regenerating planarians. Dev Dyn 218: 603-614.

SALVETTI, A., ROSSI, L., LENA, A., BATISTONI, R., DERI, P., RAINALDI, G., LOCCI, M.T., EVANGELISTA, M. and GREMIGNI, V. (2005). DjPum, a homologue of Drosophila Pumilio, is essential to planarian stem cell maintenance. Develop- ment 132: 1863-1874

SÁNCHEZ ALVARADO, A. and NEWMARK, P.A. (1999). Double-stranded RNA specifically disrupts gene expression during planarian regeneration. Proc Natl Acad Sci USA 96: 5049-5054.

SATO, K., SHIBATA, N., ORII, H., AMIKURA, R., SAKURAI, T., AGATA, K., KOBAYASHI, S. and WATANABE, K. (2006). Identification and origin of the germline stem cells as revealed by the expression of nanos-related gene in planarians. Dev Growth Differ 48: 615-628.

SHIBATA, N., ROUHANA, L. and AGATA, K. (2010). Cellular and molecular dissection of pluripotent adult somatic stem cells in planarians. Dev Growth Differ 52: 27-41.

SHIBATA, N., UMESONO, Y., ORII, H., SAKURAI, T., WATANABE, K. and AGATA K. (1999). Expression of vasa(vas)-related genes in germline cells and totipotent somatic stem cells of planarians. Dev Biol 206: 73-87.

TASAKI, J., SHIBATA, N., NISHIMURA, O., ITOMI, K., TABATA, Y., SON, F., SUZUKI, N., ARAKI, R., ABE, M., ATAGA, K. and UMESONO, Y. (2011) ERK signaling controls blastema cell differentiation during planarian regeneration. Development 138: $2417-2427$

UMESONO, Y., WATANABE, K. and AGATA, K. (1997). A planarian orthopedia homolog is specifically expressed in the branch region of both the mature and regenerating brain. Dev Growth Differ 39: 723-727.

WILSON, A., OSER, G.M., JAWORSKI, M., BLANCO-BOSE, W.E., LAURENTI, E., ADOLPHE, C., ESSERS, M.A., MACDONALD, H.R. and TRUMPP, A. (2007). Dormant and self-renewing hematopoietic stem cells and their niches. Ann N Y Acad Sci 1106: 64-75.

YADAVILLI, S., MAYO, L.D., HIGGINS, M., LAIN, S., HEGDE, V and DEUTSCH, W.A. (2009). Ribosomal protein S3: A multi-functional protein that interacts with both p53 and MDM2 through its KH domain. DNA Repair (Amst) 8: 1215-1224.

YOSHIDA-KASHIKAWA, M., SHIBATA, N., TAKECHI, K. and AGATA, K. (2007) DjCBC-1, a conserved DEAD box RNA helicase of the RCK/p54/Me31B family, is a component of RNA-protein complexes in planarian stem cells and neurons. Dev Dyn 236: 3436-3450. 


\section{Further Related Reading, published previously in the Int. J. Dev. Biol.}

Planarian regeneration: achievements and future directions after 20 years of research Emili Saló, Josep F. Abril, Teresa Adell, Francesc Cebriá, Kay Eckelt, Enrique Fernández-Taboada, Mette Handberg-Thorsager, Marta Iglesias, M Dolores Molina and Gustavo Rodríguez-Esteban Int. J. Dev. Biol. (2009) 53: 1317-1327

Expression of a retinal homeobox $(\mathbf{R x})$ gene during planarian regeneration Linda Mannini, Paolo Deri, Jacopo Picchi and Renata Batistoni Int. J. Dev. Biol. (2008) 52: 1113-1117

From Planarians to Mammals - the many faces of regeneration

Jerzy Moraczewski, Karolina Archacka, Edyta Brzoska, Maria-Anna Ciemerych, Iwona Grabowska, Katarzyna Janczyk-Ilach, Wladyslawa Streminska and Malgorzata Zimowska Int. J. Dev. Biol. (2008) 52: 219-227

Expression of DjXnp, a novel member of the SNF2-like ATP-dependent chromatin remodelling genes, in intact and regenerating planarians

Leonardo Rossi, Paolo Deri, Ilaria Andreoli, Vittorio Gremigni, Alessandra Salvetti and Renata Batistoni

Int. J. Dev. Biol. (2003) 47: 293-298

Effects of activators and antagonists of the neuropeptides substance $P$ and substance $\mathrm{K}$ on cell proliferation in planarians

J Baguñà, E Saló and R Romero

Int. J. Dev. Biol. (1989) 33: 261-266

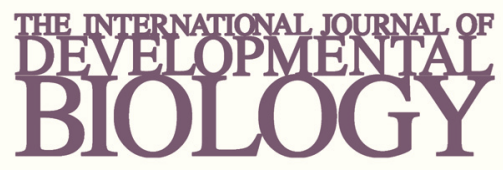

Volume 54 Nos. 6/7
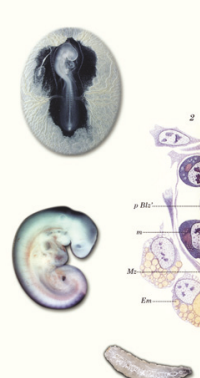

Developmental Hematopoiesis
Special Issue
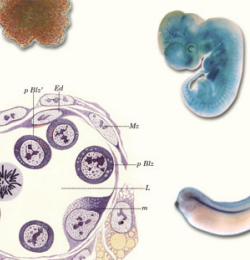

(.)

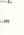

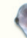
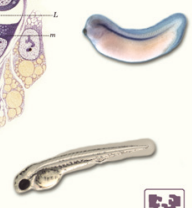

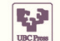

5 yr ISI Impact Factor $(2010)=2.961$

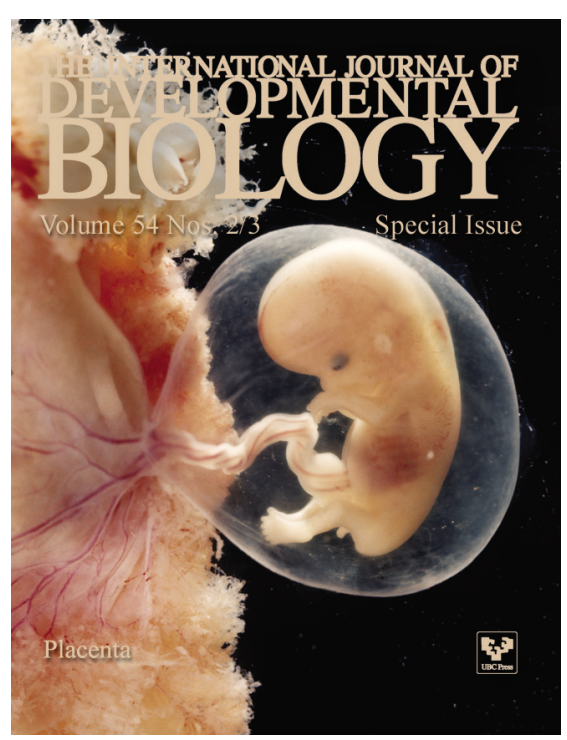

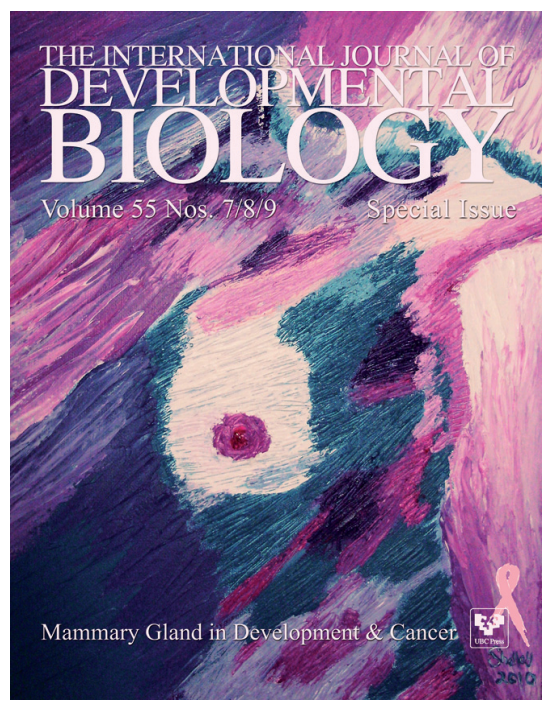

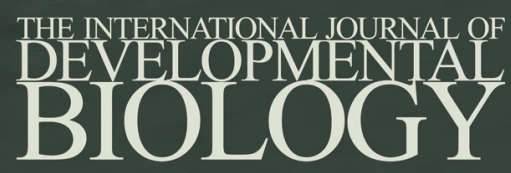

Volume 55 Nos. $4 / 5$

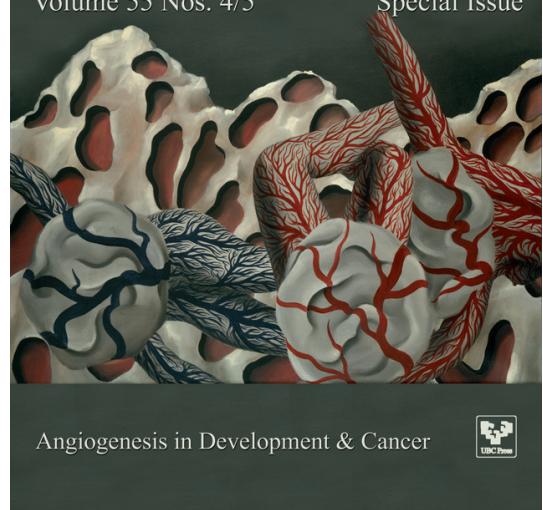

